\title{
Cutaneous Crohn's Disease and Anogenital Granulomatosis with Crohn's Disease: Many Names for the Same Clinical Entity
}

\section{Makiko Asakura, Kazuko Sakimoto, Hiroyuki Miura*}

Department of Dermatology, Kinki Central Hospital, Itami, Japan.

Email: ${ }^{*}$ miura_h@kich.itami.hyogo.jp

Received March 23 ${ }^{\text {rd }}, 2012$; revised April 22 ${ }^{\text {nd }}, 2012$; accepted May $1^{\text {st }}, 2012$

\begin{abstract}
Anogenital granulomatosis (AGG) is a rare chronic idiopathic disorder presenting as a painless swelling of the vulva, labia, penis, and/or anogenital area. Some AGG cases have been diagnosed along with Crohn's disease (CD). We report a case of AGG that led to diagnosis of underlying CD, namely Cutaneous Crohn's disease (CCD). We guess that CCD appeared in the anogenital region is equal to AGG with $\mathrm{CD}$.
\end{abstract}

Keywords: Anogenital Granulomatosis; Crohn's Disease; Cutaneous Crohn's Disease

\section{Introduction}

Anogenital granulomatosis (AGG) is a rare chronic idiopathic disorder presenting as a painless swelling of the vulva, labia, penis, and/or anogenital area, histologically characterized by noncaseating giant cell granulomas in the dermis [1]. Some AGG cases have been diagnosed along with Crohn's disease (CD); however, it is uncertain whether AGG develops as a manifestation of CD or occurs independently.

We report a case of AGG that led to diagnosis of underlying $\mathrm{CD}$, namely Cutaneous Crohn's disease (CCD).

\section{Case Report}

A 13-year-old Japanese girl presented with a history of relapsing swelling of the left labium majus and anoperineal area for a year and poor digestion and iron deficiency anemia for a few years. Examination revealed a reddish and edematous left labium majus and anoperineal area with induration and mild tenderness (Figure 1).

Blood tests revealed a low protein level (TP, $5.7 \mathrm{~g} / \mathrm{dl}$; Alb, $2.9 \mathrm{~g} / \mathrm{dl})$ and iron deficiency anemia $(\mathrm{Hb}, 7.6 \mathrm{~g} / \mathrm{dl}$; $\mathrm{Fe}, 8 \mu \mathrm{g} / \mathrm{dl})$. The serum CRP level was elevated to 4.97 $\mathrm{mg} / \mathrm{dl}$ (normal $<0.3 \mathrm{mg} / \mathrm{dl}$ ).

A biopsy of the lesion revealed noncaseating granulomas with multinucleated giant cells consistent with the diagnosis of anogenital granulomatosis (Figure 2). Therefore, inflammatory bowel disease was suspected and we consulted the department of internal medicine. The pa-

"Corresponding author.

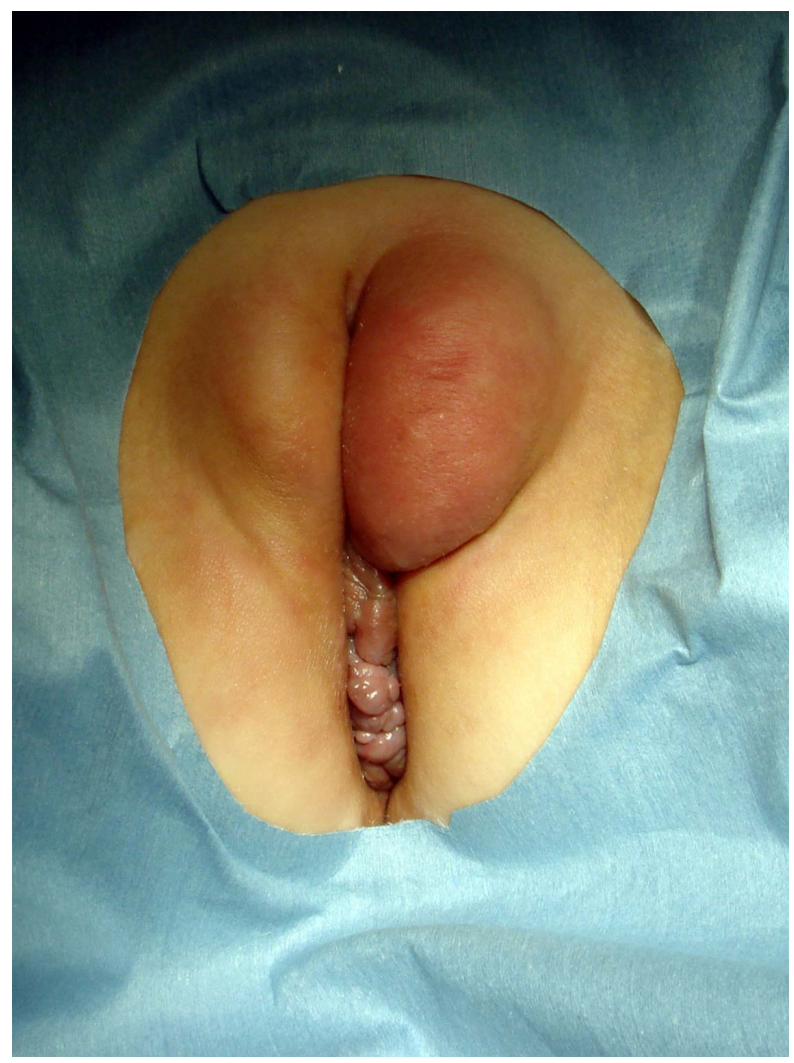

Figure 1. Clinical appearance of the labium majus and anoperineal area.

tient was diagnosed with underlying $\mathrm{CD}$ and treated with systemic infliximab. The bowel and cutaneous lesions 


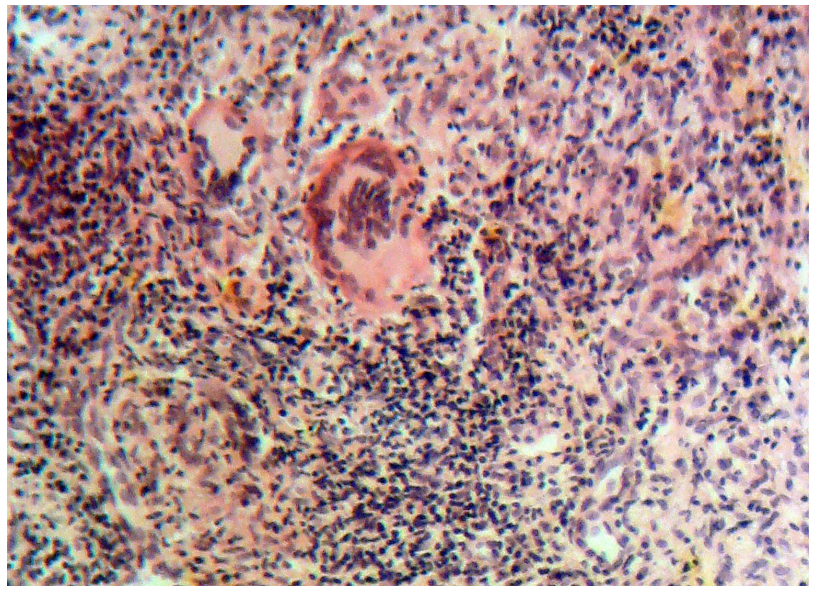

Figure 2. Biopsy specimen showing noncaseating granulomas with multinucleated giant cells in the dermis $(H \& E$ staining, original magnification $\times \mathbf{2 0 0}$ ).

responded well to treatment.

\section{Discussion}

The term "anogenital granulomatosis" implies the possibility of several underlying etiologies, and this disease entity has been previously recognized as vulvitis granulomatosa or Melkersson-Rosenthal vulvitis, among other designations [1,2]. CCD, or metastatic Crohn's disease, is not distinguishable from AGG pathologically [1-4], and we assume they are also similar or same entity of AGG. Although not every patient diagnosed with AGG exhibits the gastrointestinal manifestations of $\mathrm{CD}[1,2]$, it is uncertain whether $\mathrm{AGG}$ is a manifestation of $\mathrm{CD}$ or occurs independently. We guess that $\mathrm{CCD}$ appeared in the anogenital region is equal to $\mathrm{AGG}$ with $\mathrm{CD}$, therefore our case had been recognized as CCD after identified the underlying CD.

According to an examination of previous case reports, $55.5 \%(10 / 18)$ of cases of AGG present with CD in less than twenty years old and 9.5\% (2/21) present above twenties years of age [1], suggesting that younger patients have a higher risk of developing AGG with underlying CD.

In our patient, by the time AGG was diagnosed, two or three years had passed since digestive symptoms had appeared and one year had passed since the appearance of skin symptoms. However, this patient was not diagnosed or treated for CD. In cases where AGG is diagnosed, especially in childhood, physicians should perform careful examinations to identify the possible underlying systemic disorders.

\section{REFERENCES}

[1] M. R. van de Scheur, R. I. F. van der Waal and I. van der Waal, "Ano-Genital Granulomatosis: The Counterpart of Oro-Facial Granulomatosis," Journal of the European Academy of Dermatology and Venereology, Vol. 17, No. 2, 2003, pp. 184-189. doi:10.1046/j.1468-3083.2003.00573.x

[2] A. R. Günthert, et al., "Vulvitis Granulomatosa and Unilateral Hypertrophy of the Vulva Related to Crohn's Disease: A Case Report," American Journal of Obstetrics \& Gynecology, Vol. 191, No. 5, 2004, pp. 1719-1720.

[3] R. M. Vaid and B. A. Cohen, "Cutaneous Crohn's Disease in the Pediatric Population," Pediatric Dermatology, Vol. 27, No. 3, 2010, pp. 279-281. doi:10.1111/j.1525-1470.2010.01138.x

[4] A. L. Pinna, L. Atzori, C. Ferreli and N. Aste, "Cutaneous Crohn's Disease in a Child," Pediatric Dermatology, Vol. 23, No. 1, 2006, pp. 49-52. doi:10.1111/j.1525-1470.2006.00170.x 